\title{
MEASUREMENT OF INFERIOR VENA CAVA DIAMETER BY ULTRASOUND IN INTENSIVE CARE UNIT PATIENTS WITH PNEUMONIA
}

\author{
By

\begin{abstract}
Mohamed Zakaria Mohamed Hamed, Imam Abd El-Kader El-Sherief, Moaz Atef El-Shahat Abd El-Aty and Ahmed Mohamed EL-Deeb.
\end{abstract}

\author{
Department of Chest, Faculty of Medicine, Al-Azhar University, Cairo, Egypt
}

Corresponding author: Mohamed Zakaria Mohamed Hamed,

Mobile: (+20)01050477433), E-mail: dr.mohamed.zak203@gmail.com

\begin{abstract}
Background: Pneumonia is an inflammatory condition of the lung affecting primarily the alveoli, typically symptoms include combination of cough, chest pain, fever, and trouble breathing, Fluid resuscitation in critically ill patients is common and serious challenge so measurements of central venous pressure (CVP), pulmonary arterial catheterization, esophageal Doppler ultrasonography (Ultrasound)and trans esophageal echocardiography may be used to determine the volume status of critically ill patients.
\end{abstract}

Objective: To determine the value of measurement of IVC diameter by ultrasound as a noninvasive tool in assessment of intravascular volume and hydration status in ICU patients with pneumonia.

Patients and Methods: This prospective cross-sectional study was carried out in the Intensive Care Units of Chest Department, at Al- Hussein and Bab Al-sha'reia University Hospitals, during the period from November 2019 to September 2020, and included sixty persons: Thirty patients with pneumonia (diagnosed on clinical and radiological basis), and another thirty apparently healthy subjects collected from Hospital persons or patients relative matching with age, sex and body mass index. Body mass index ultrasound measurement of Inferior vena cava diameter was done for all.

Results: There was significance decrease of inspiratory IVC-D in patient's group than control's group (mean inspiratory IVC-D of patients $0.63 \mathrm{~cm}$ versus $0.92 \mathrm{~cm}$ in control's group). Also, there was significant decrease of expiratory IVC-D in patient's group than control's group (mean expiratory IVC-D in patient's group $1.46 \mathrm{~cm}$ versus $1.68 \mathrm{~cm}$ in the control's group). The IVC-CI of the patient's group in this study had highly significant increase than control's group (66\% versus $46 \%)$.

Conclusion: Assessment of the physiologic characteristics of the IVC by ultra sound provides a rapid distinction between low and high volume states and offers a rapid, easily, reliable and noninvasive way to guide resuscitation in patients with pneumonia.

Key words: Pneumonia; Intensive Care Unit; Ultrasound; Inferior Vena Cava Diameter.

\section{INTRODUCTION}

A clinical definition of pneumonia is two or more of the following symptoms/physical findings: Productive cough, purulent sputum, dyspnea or tachypnea, rigors or chills, and pleuritic chest pain in conjunction with a new opacity on chest radiograph (Thomas, 2015). Fluid resuscitation in critically ill patients is common and serious challenge. Reduced organ perfusion may result from hypovolemia and dehydration, while complications such as pulmonary edema 
may result from over hydration (Wiedeman, 2016). Ultrasound measurements of the IVC diameter by bedside ultrasound are an easy, fast, reliable and noninvasive method for assessing patient's volume status and not associated with complications. In addition, many emergency departments have Ultrasound systems that can easily be used by emergency physicians (Shoemaker et al., 2016).

The present work aimed to determine the value of measurement of IVC diameter by ultrasound as a noninvasive tool in assessment of intravascular volume and hydration status in ICU patients with pneumonia.

\section{PATIENTS AND METHODS}

This study was conducted at Chest Department, Al-Azhar University (AlHussein and Bab Alshaaria University Hospitals) during the period between November 2019 to September 2020, and included two groups: Group (1): Patient's group: Thirty patients with pneumonia randomly selected (diagnosed on clinical and radiological basis), and Group (2): Control's group: Thirty apparently healthy subjects collected from Hospital persons or patient relatives, matching with sex and body mass index.

Exclusion criteria: Patients with any of the following were totally excluded from the study; Patients aged Less than 18 years old, cardiac co morbidities, chronic chest diseases, renal failure and Hepatomegaly, morbid obesity (B.M.I. above $40 \mathrm{~kg} / \mathrm{m} 2$ ), Patients with raised intra-abdominal pressure such as pregnancy, ascites, abdominal distension, gastropareisis (ileus or pseudo
obstruction).

Inclusion criteria: Patients equal or more than 18 years old, BMI between 20$40 \mathrm{~kg} / \mathrm{m} 2$, patients with pneumonia admitted in ICU.

\section{Methods:}

The study was approved by The Ethics Committee of Al-Azhar University, Faculty of Medicine. After explanation of the procedure to the patients, a written or verbal consent for participation in this study was obtained by every patient. If the patient was conscious or by relatives if the patient was unconscious. All patients underwent the following: Full history and clinical examination, routine laboratory tests $\mathrm{CBC}$, liver function tests, kidney function tests and urine output, assessment of severity of pneumonia according to CURB-65 score, sputum culture and examination, chest radiograph (PA, lateral views), oxygen saturation by pulse oximetry and arterial blood gases, ultrasound measurement of inferior vena cava (IVC) diameter by $\mathrm{B}$ mode $2-3 \mathrm{~cm}$ before the point of entry of the IVC into the right atrium, echocardiography, body mass index, clinical evaluation of intraabdominal pressure. All patients in control group had undergone ultrasound measurement of inferior vena cava diameter and, body mass index.

\section{Calculation of IVC-CI for patients and control groups:}

Methods of Measuring IVC diameter and CI: The inferior vena cava (IVC) diameter measured in a supine patient in the sagittal (long-axis) subxyphoid window, making sure to angle the transducer to the patient's right. The 
technique was performed using curvilinear or convex probe. The IVC visualized in a longitudinal view at the level of the cavalright atrial junction. The anteroposterior diameter of inferior vena cava (IVCD) was measured duplicately, using images frozen according to operator judgment, at the end of inspiration (iIVCD) and the end of expiration (eIVCD) in a subxiphoid location in the longitudinal axis where the anterior and posterior wall of the IVC are easily visualized and lie parallel to each other. The IVC diameter (IVC D) was measured during inspiration and during expiration at a distance of $2-3 \mathrm{~cm}$ from the IVC right atrial junction in the long axis. In a spontaneously breathing patient, negative intrathoracic pressure generated during inspiration draws blood from the IVC into the right atrium, resulting in varying degrees of IVC collapse. Measurements of IVC collapse are commonly reported as the collapsibility index, which is calculated as (maximum IVC diameter on expiration - minimum IVC diameter on inspiration/maximum IVC diameter on expiration). In contrast, during mechanical ventilation, the force of inspiration was generated by positive pressure and the IVC distends rather than collapsed. Studies of IVC respirophasic variation in mechanically ventilated patients (IVC dispensability) were typically performed with fixed tidal volume in adequately sedated patients with controlled ventilation. In mechanically ventilated patients, the dispensability index was calculated as maximum IVC diameter on inspirationminimum IVC diameter on expiration/ minimum IVC diameter on expiration. The term caval index (CI) has been used to refer respirophasic changes in IVC diameter irrespective of the patient was spontaneously breathing or mechanically ventilated.

Statistical analysis: Data were collected; coded, revised, verified and computerized, statistical analysis of data was performed using Statistical pachage for the Social Science (SPSS) version 24. Quantitative data were expressed as mean \pm standard deviation (SD), range, median, and interquartile range (IQR). Qualitative data were expressed as frequency and percentage, P-values $\leq 0.05$ were considered significant. Independent sample t-test was used in comparing the means of two groups or Mann-Whitney $u$ Test.

\section{RESULTS}

Sixty persons were included in this study and were equally divided into patients and control groups, the mean age of patient's group was (58.9) in males and (58.4) in females while in control's group, the mean age was (38.75) in males and (43) in females. The mean BMI of patient's group was (25.2) in males and (29) in females, while in control's group, the mean BMI (24) in males and (26.5) in females. The mean $\mathrm{PaO} 2$ in patient's group in males was $(50.4 \mathrm{mmHg})$ and in females was $(52.6 \mathrm{mmHg})$. The mean $\mathrm{PaCO} 2$ in patient's group was $(36 \mathrm{mmHg})$ in males and $(33.4 \mathrm{mmHg})$ in females. The mean $\mathrm{pH}$ in patients group was (7.3) in males and (7.4) in females. The mean $\mathrm{Hb}$ in patient's group was $(9.7 \mathrm{~g} / \mathrm{dl})$ in males 
and in females was $(10.9 \mathrm{~g} / \mathrm{dl})$. The mean WBCs in patient's group was (16.3 $\mathrm{x} 103 / \mathrm{ul})$ in males and $(13.9 \mathrm{x} 103 / \mathrm{ul})$ in females. The chest $\mathrm{x}$-ray result in patient's group; according to side of lesions, RT lung in (16), LT lung in (5), while bilateral in (9). The lesions were pneumonic patch, bilateral diffuse infiltration and pleural effusion, the consolidation was recorded $81 \%$ of CXR. There was presence of Chest ultrasonography consolidation in (90\%) and pleural effusion in $(40 \%)$ of patient's group. Patient's group according to CURB-65 score divided to CURB-65 (2): two patients $6.67 \%$, CURB-65(3): twenty patients $66.65 \%$, CURB-65(4): four patients 13.34\%, CURB-65(5): four patients $13.34 \%$. The mean inspiratory IVC-D for patient's group was $(0.63 \mathrm{~cm})$ and the mean inspiratory IVC-D for control's group was $(0.92 \mathrm{~cm}), \quad(\mathrm{p}-$ value $<0.001)$. There was highly statistically significant decrease of IVC-D during inspiration in patient's group than control's group (Table 1).

Table (1): Statistical study of IVC - D during inspiration between patients and control groups

\begin{tabular}{|c|c|c|}
\hline Groups & $\begin{array}{c}\text { Patients } \\
(\mathbf{n = 3 0})\end{array}$ & $\begin{array}{c}\text { Control } \\
(\mathbf{n = 3 0})\end{array}$ \\
\hline IVC- D inspiration & $0.3-1.1$ & $0.55-1.5$ \\
\hline Range & 0.63 & 0.92 \\
\hline Mean & 0.21 & 0.24 \\
\hline SSD & 0.038 & 0.044 \\
\hline $\begin{array}{c}|c| \\
\text { SE }\end{array}$ & \multicolumn{2}{|c|}{$<0.001$} \\
\hline $\begin{array}{c}|c| \\
\text { means }\end{array}$ & \multicolumn{2}{|c|}{} \\
\hline p-value & \multicolumn{2}{|c|}{} \\
\hline
\end{tabular}

$\mathrm{T}$ : independent sample test.

The mean expiratory IVC-D for patient's group was $(1.46 \mathrm{~cm})$ and the mean expiratory IVC-D for control's group was $(1.68 \mathrm{~cm})$, (p-value $<0.007)$,
There was statistically significant decrease of IVC- D during expiration in patient's group than control's group (Table 2).

Table (2): Statistical study of IVC - D during expiration between patients and control groups

\begin{tabular}{|c|c|c|}
\hline Groups & $\begin{array}{c}\text { Patients } \\
(\mathbf{n = 3 0})\end{array}$ & $\begin{array}{c}\text { Control } \\
(\mathbf{n = 3 0})\end{array}$ \\
\hline Range & $1.1-2$ & $1.05-2.25$ \\
\hline Mean & 1.46 & 1.68 \\
\hline $\mathbf{\pm S D}$ & 0.27 & 0.33 \\
\hline SE & 0.049 & 0.06 \\
\hline Observative difference between means & \multicolumn{2}{|c|}{0.22} \\
\hline p-value & \multicolumn{2}{|c|}{0.007} \\
\hline
\end{tabular}

T: independent sample test. 
The mean IVC-CI for patient's group was $(65.8 \%)$ and the mean IVC-CI for control's group was $(45.5 \%)$, (p-value <
0.001). There was highly significant increase of IVC caval index in patient's group than control's group (Table 3).

Table (3): Statistical study of IVC Collapsibility Index between patients and control groups

\begin{tabular}{|c|c|c|}
\hline Groups & $\begin{array}{c}\text { Patients } \\
(\mathrm{n}=30)\end{array}$ & $\begin{array}{c}\text { Control } \\
(\mathrm{n}=30)\end{array}$ \\
\hline I V C Collapsibility Index & $45-100$ & $33.3-54.9$ \\
\hline Range & 65.8 & 45.5 \\
\hline Observative difference between means & \multicolumn{2}{|c|}{20.3} \\
\hline Median & 64.4 & 46.5 \\
\hline IQR & $56.3-73.3$ & $42.7-48.6$ \\
\hline Statistical. Test & \multicolumn{2}{|c|}{ MW $=32$} \\
\hline p-value & \multicolumn{2}{|c|}{$<001$} \\
\hline
\end{tabular}

MW: Mann-Whitney Test.

The previous results confirmed that patients with Pneumonia who admitted to ICU had decrease in IVC-D and increase

\section{DISCUSSION}

The IVC diameter is dependent on the total body fluid volume, the caval opening increases in width during inspiration (which encourages venous return of blood to the heart), The negative intrathoracic pressure leads to collapse of the IVC. During expiration the reverse happens causing distension of the IVC (Gray's anatomy, 2018).

This study was designed to determine the value of measurement of IVC diameter by ultrasound as a noninvasive tool in assessment of intravascular volume and hydration status in ICU patients with pneumonia. The IVC diameters (IVC-D) were measured during inspiration and during expiration at a distance of $2-3 \mathrm{~cm}$ from the IVC right atrial junction in the long axis. Measurements in non-intubated patients were obtained during their normal spontaneous inspiration and expiration while trying to avoid Valsalva maneuvers. in IVC -CI due to dehydration and unstable hemodynamic.

Ventilate patients were evaluated during normal ventilator cycling. The size and shape of the inferior vena cava (IVC) is correlated to the CVP and circulating blood volume. The IVC is a highly compliant vessel with no valve whose size varies easily with changes of intravascular pressure. As a result, normal respiratory cycle causes changes in intra- thoracic pressure which in turn influence venous return from the IVC and also affect the variation of IVC diameter. Consequently, the IVC collapses with inspiration as the blood is pumped out of the IVC due to the negative pressure created by chest expansion. In healthy subjects breathing spontaneously, cyclic changes in thoracic pressure may result in collapse of the IVC diameter of approximately $50 \%$ (Lyon and Verma, 2012).

The demographic data in this study revealed that the mean age of the included male patients was 58.9, and the mean age of the included female patients was 58.4, 
while in control group, the mean age of males was 38.75 , and the mean age of females was 43 . The cause of difference of ages between the two groups may be due to that the pneumonia is common to occur in old age. The same observation was reported by Pagano et al. (2015) who found that the mean age of patients is $58 \pm 21$ years old. Analysis of data by Nafae et al. (2013) in studying patients with pneumonia admitted to ICU found that, the age was more than 50 years old and males were predominant in presentation.

The mean BMI of the male patients was 25.2, and the mean BMI of female patients was 29 , while in control group, the mean BMI of males was 24, and the mean BMI in females was 26.5. In the current study, $46.7 \%$ patients were smokers, while in the control group there were $33.3 \%$ smokers. These could be explained by the fact that smoking and addiction are more prone to respiratory illnesses. Elshabrawi et al. (2017) found that smokers were $35 \%$ of their patients with mean age were 25 years old. This may be the cause of this difference.

All patients in the current study were hypotensive, the mean SBP was 100 $\mathrm{mmHg}$ and the mean DBP was $65 \mathrm{mmHg}$. Karacabey et al. (2016) recorded that, the mean SBP was $117 \mathrm{mmHg}$ (ranges from $60-220 \mathrm{mmHg}$ ), and the mean DBP was $70 \mathrm{mmHg}$ (ranged from $30-140$ ). Nearly, the same result of the present study was recorded by Elshabrawi et al. (2017) on studying patients with CAP, and they found that the mean SBP was $106 \mathrm{mmHg}$ and the mean DBP was $64 \mathrm{mmHg}$.

Hypoxia, hypocapnia and normal $\mathrm{PH}$ were observed in patients of the present study as the means $\mathrm{PaO} 2$ were 50.4 $\mathrm{mmHg}$ and $52.6 \mathrm{mmHg}$ in male and female patients respectively. The means $\mathrm{PaCO} 2$ were $36 \mathrm{mmHg}$ and $33.4 \mathrm{mmHg}$ in male and female patients respectively. The means of PH were 7.3 and 7.4 in male and female patients respectively; similar hypoxemia was reported in patients with pneumonia by Pagano et al. (2015) who found that the mean $\mathrm{PaO} 2$ was $55 \mathrm{mmHg}$.

Anemia and leukocytosis were common in patients of the current study. The mean hemoglobin was $9.7 \mathrm{gm} / \mathrm{dl}$ and $10.9 \mathrm{gm} / \mathrm{dl}$ in male and female patients respectively, the mean WBCs was $16.3 \times 103 /$ ul and $13.9 \times 103 /$ ul in male and female patients respectively. Leukocytosis also was reported by Pagano et al. (2015) who found that the mean TLC was $11.5 \times 103 /$ ul .

The present study showed that the chest $\mathrm{X}$ ray resulted in patient's group were $10 \%$ in upper lobe pneumonic patch in the right lung. $26.66 \%$ upper and middle lobes pneumonic patch in the right lung, $16.67 \%$ middle and lower lobes pneumonic patch in the right lung and $16.67 \%$ upper and lower lobes pneumonic patch in the left lung, $30 \%$ of patients were presented with bilateral diffuse infiltration, $26.66 \%$ of patients had associated right sided pleura effusion, while $13.33 \%$ of them had associated left sided pleura effusion. The consolidation was recorded in $81 \%$ of patients by CXR. In the present study $90 \%$ of pneumonic patients showed ultrasonographic signs of consolidation. Therefore, ultrasonography was sensitive in diagnosis of pneumonia than CXR. Nafae et al. (2013) on studying patients with CAP diagnosed by CT chest confirmed the results of the current study, 
and found that 78 of their patients had positive criteria of pneumonia by LUS $(97.5 \%)$ versus 62 patients by CXR $(77.5 \%)$. Also, the same results were reported by Liu and Lian (2015) while comparing the accuracy of LUS and CXR for the diagnosis of CAP and concluded that the LUS was found to be better than CXR (sensitivity of 94.6 versus $77.7 \%$ ). In addition, Bourcier et al. (2014) on studing the duration of the symptoms with respective performance of LUS and CXR for diagnosis of CAP, they observed that LUS detected more cases of CAP than CXR in the first 24 hours $76 \%$ vs $25 \%$. These results were also suggestive that LUS was more sensitive than CXR in early diagnosis of CAP. During the follow up of patients with CAP. Reissig et al. (2012) found that LUS was more effectively monitor the changes of lesions early. Wang et al. (2016) concluded that LUS helps to reduce the overexposure of patients to radiation. Therefore, the use of LUS as a standard of care should be encouraged, especially in the ICU.

The sputum culture results in the included patients showed that $10 \%$ of them were diagnosed to have Staph aureus (MRSA), 16.67\% had Pseudomonas, $13.34 \%$ had Acinetobacter, $13.34 \%$ had Klebsiella, $3.33 \%$ had Candida, while $43.32 \%$ of them revealed negative culture, CURB-65 score three or more was observed in $93 \%$ of patients in the present study and six patients of them were intubated, Elshabrawi et al. (2017) found that CURB-65 score three or more was present only in $30 \%$ of their patients and 12 out of 40 patients were intubated. This difference owing to that the patients in this study were old age and suffering from severe pneumonia .
In the current study, there was highly significance decrease of inspiratory IVC$\mathrm{D}$ in patient's group than control's group (mean inspiratory IVC-D of patients 0.63 $\mathrm{cm}$ versus $0.92 \mathrm{~cm}$ in control group), Also there is significant decrease of expiratory IVC-D in patient's group than control's group (mean expiratory IVC-D in patient's group $1.46 \mathrm{~cm}$ versus $1.68 \mathrm{~cm}$ in the control's group), this mean that patients in the current study were suffering from dehydration and hemodynamic instability. The same results of control group of the present study was observed by Gnanasekaran et al. (2016) on healthy indian subjects of different ages, found that the mean inspiratory IVC-D was $0.81 \mathrm{~cm}$ and the mean expiratory IVC-D was $1.67 \mathrm{~cm}$. On the other hand, Yamanoglu et al. (2014) when measuring the inspiratory and expiratory IVC-D of patients with severe dyspnea due to pulmonary disease $\quad(30 \%$ with pneumonia), they found that inspiratory and expiratory IVC-D were $(0.44 \mathrm{~cm} \& 1.1 \mathrm{~cm}) \quad$ respectively. The expiratory IVC-D of their study was the same as the present study but the inspiratory IVC-D was less than that of the current study $(0.44$ versus $0.64 \mathrm{~cm})$, this may be due to most of their patients was suffering from severe dyspnea which explain the cause of increase IVC-CI $(74 \%)$ of their patients. The IVC-CI of the patient's group in this study had highly significant increase than control's group (66\% versus $46 \%$ ). As regard to control's group, IVC-CI $46 \%$ also reported by Ganasekaran et al. (2016) on studying Indian normal subjects. On the other hand patients with hypovolemia had IVC-CI of $68,1 \%$ in studying of Nagadev et al. (2014), and they conceded that an IVC - 
CI of equal or greater than $50 \%$ was strongly associated by CVP less $8 \mathrm{~cm}$ H2O. Elshabrawi et al. (2017) on studing patients with pneumonia observed that patients with CURB-65 score (1) had mean IVC-CI was $37.5 \%$ and 15 patients with CURB-65 score $(\geq 2)$ had mean IVCCI was $61.5 \%$. The mean IVC-CI \% of the present study was nearly the same as that of patients of CURB-65 score $(\geq 2)$. This explains that why all patients in the present study were admitted to ICU as they were suffering from severe pneumonia than those of the previous study.

\section{CONCLUSION}

Earlier measurement of IVC diameter and collapsibility index may have an improve management of patients with pneumonia particularly in case of dehydration. Assessment of the physiologic characteristics of the IVC by ultra sound provides a rapid distinction between low and high volume states and offer a rapid, easily, reliable and noninvasive way to guide resuscitation in patients with pneumonia. Adding IVC-CI to severity indices may improve their prognostic value. Adding IVC-CI to CURB-65 creates a new score like (Modified CURB-65 or CURB -CI).

\section{REFERENCES}

\section{Bourcier JE, Paquet J, Seinger MY and} Gallard E (2014): Performance comparison of lung ultrasound and chest $\mathrm{x}$-ray for the diagnosis of pneumonia in the ED. Am J Emerg Med.,32:115-8.

2. ElshabrawiA, Hussein $\mathbf{H}$, Hussien $\mathrm{S}$ and Ewis A (2017): Study of Inferior Vena Cava Collapsibility Index in Patients with Community Acquired Pneumonia in Al-Azhar University
Hospital in Damietta. Nat Sci.,15(1):8994.

3. Gnanasekaran N, Neelakandan A, Subbaraman $S$ and Lasya $T$ (2016): Measurement of inferior vena cava parameters in the normal adult Indian population using transabdominal ultrasound: A standardisation study. J. Evid. Based Med. Healthc., 3(55), 27952803.

4. Gray's anatomy (2018): The anatomical basis of clinical practice (40th Ed.). Pbl London: Churchill Livingstone.

5. Karacabey S, Sanri $E$ and Guneysel $O$ (2016): A non-invasive method for assessment of intravascular fluid status: Inferior vena cava diameters and collapsibility index. Pakistan Journal of Medical Sciences, 32(4): 836 - 845.

6. Liu XL and Lian R (2015): Lung ultrasonography: an effective way to diagnose community-acquired pneumonia. Emerg Med J., 32:433-8.

7. Lyon ML and Verma $N$ (2012): Ultrasound guided volume assessment using inferior vena cava diameter. Open Emerg Med J., 3:22-4.

8. Nafae R, Shebl E, Mohamad N and ElGhamry R (2013): Adjuvant role of lung ultrasound in the diagnosis of pneumonia in intensive care unit-patients. Egyptian Journal of Chest Diseases and Tuberculosis., 62(2): 281-285.

9. Nagdev A, Roland C, Tirado-Gozalez A and Sisson A (2014): Emergency department bedside ultrasonographic measurement of the caval index for noninvasive determinant of low central venous pressure. Ann Emerg Med., 55: (3): 290-295.

10. Pagano A, Numis FG, Visone G, Pirozzi C, Masarone M, Olibet M and Paladino F (2015): Lung ultrasound for diagnosis of pneumonia in emergency 
department. Internal and Emergency Medicine., 10(7): 851-854.

11. Reissig A, Copetti R, Mathis G, Mempel C, Schuler A, Zechner $P$ and Hoyer $H$ (2012): Lung ultrasound in the diagnosis and follow-up of communityacquired pneumonia: a prospective, multicenter, diagnostic accuracy study. Chest, 142(4): 965-972.

12. Shoemaker WC, Chien $L$ and $L u K$ (2016): Evaluation of invasive and noninvasive hemodynamic monitoring in trauma patients. J Trauma.,61 (4):844853.discussion 53-54.

13. Thomas M (2015): Acute Bronchitis and Community-Acquired Pneumonia', in Fishman's Pulmonary Diseases and Disorders, (5th Ed.). Pbl. McGraw-Hill Education, pp 1966-1980.
14. Wang G, Ji $X, X u Y$ and Xiang $X$ (2016): Lung ultrasound: a promising tool to monitor ventilator-associated pneumonia in critically ill patients. Critical Care, 20(1): 320 - 335.

15. Wiedeman H P (2016): National Heart, Lung, and Blood Institute acute respiratory distress syndrome (ARDS) clinical trials network, comparison of two fluid-management strategies in acute lung injury. N Engl J Med., 354(24): 25642575.

16. Yamanoğlu A, Yamanoğlu N, Parla I and Pinar $P$ (2014): The role of inferior vena cava diameter in the differential diagnosis of dyspneic patients; best sonographic measurement method? American Journal of Emergency Medicine., 33 (3): 396-401. 


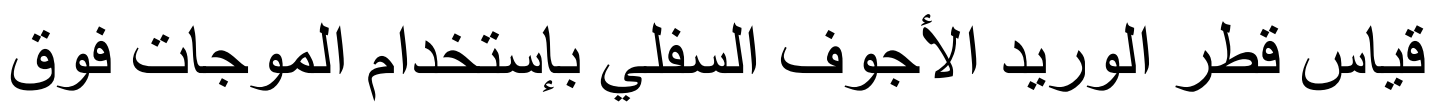
الصوتية في مرضسى الإلتهاب الرئوي بالر بالر عاية المركزة

محمد زكريا محمد حامد، إمام عبد القادر الثريف، معاذ عاطف الشحات عبد العاطي، أحمد محمد الايب

قسم الأمراض الصدرية، كلية الطب، جامعة الأزهر، القاهرة

E-mail: dr.mohamed.zak203@gmail.com

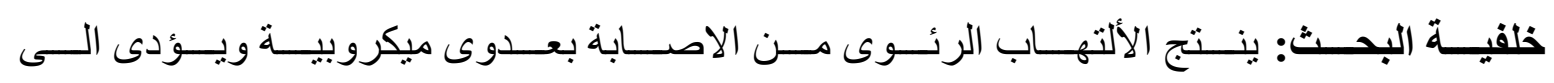

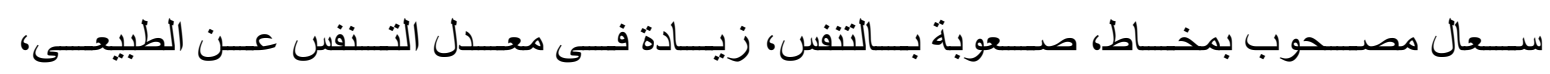

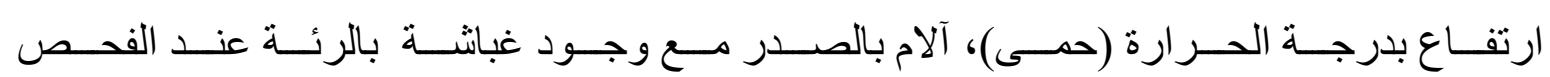

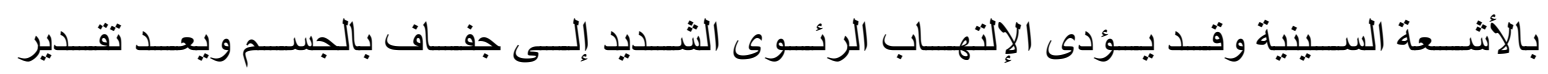

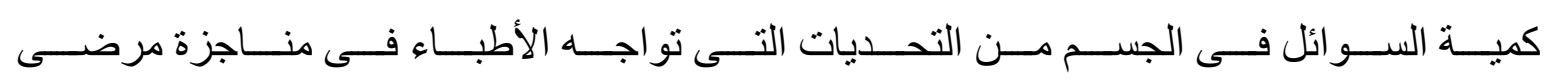

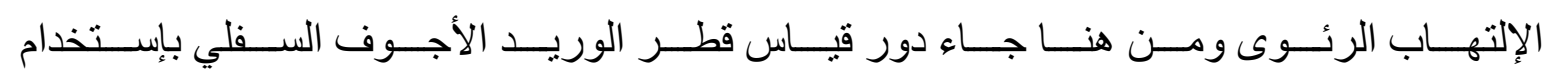

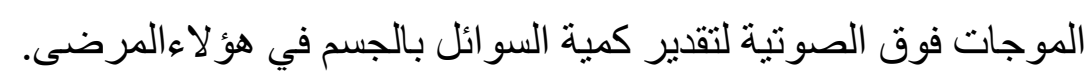

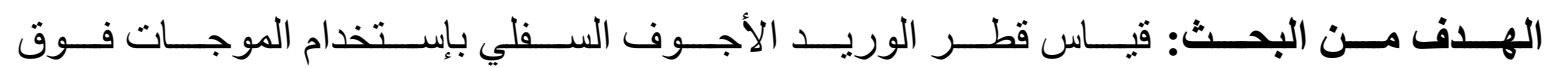
الصوتية في مرضى الإلتهاب الرئوي بالر عاية المركزة.

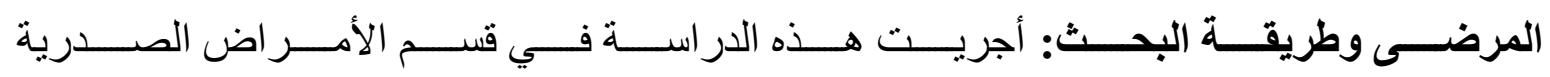

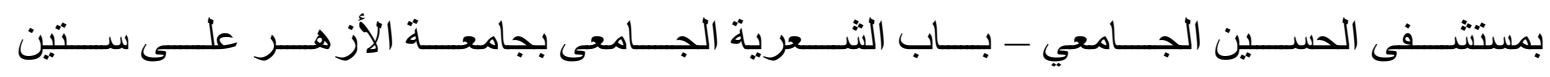

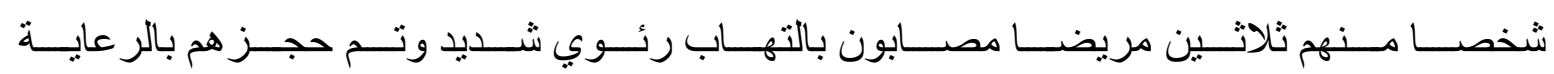

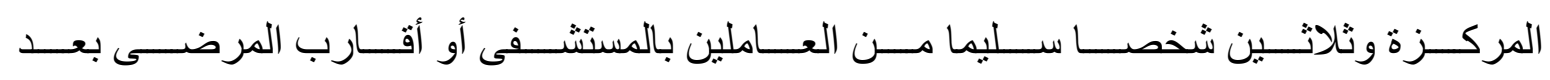

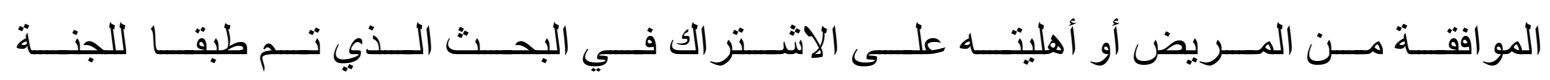

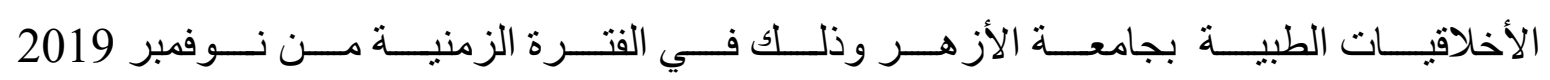

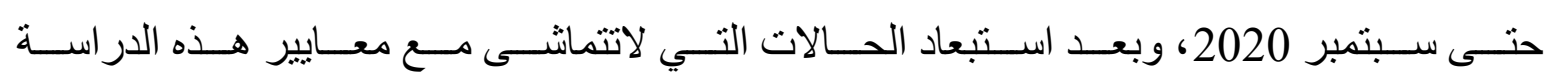

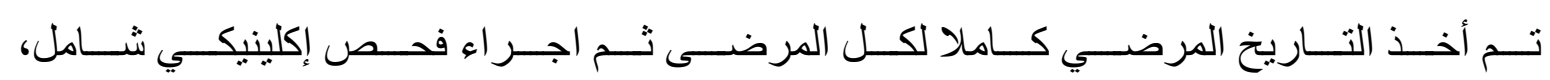

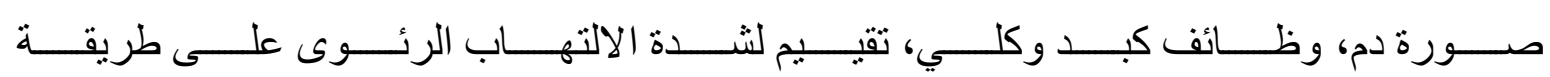

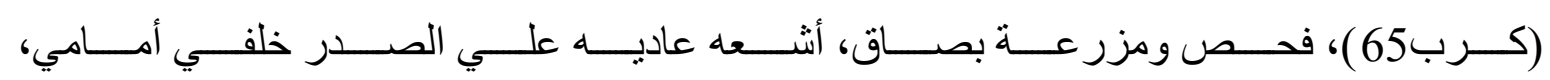

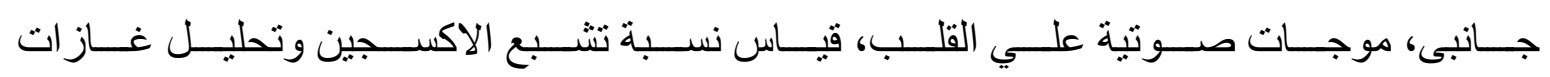




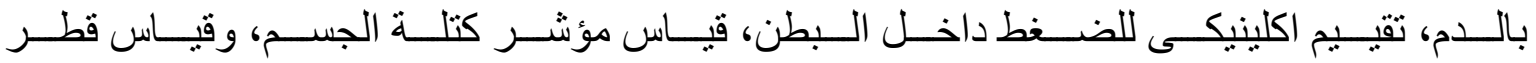

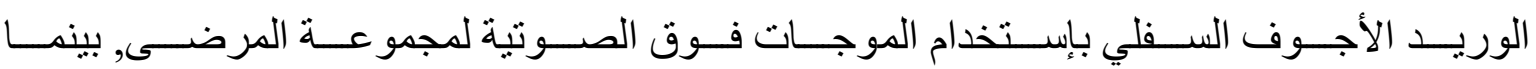

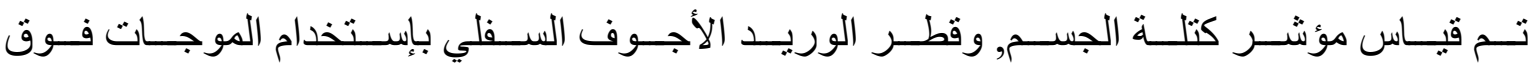

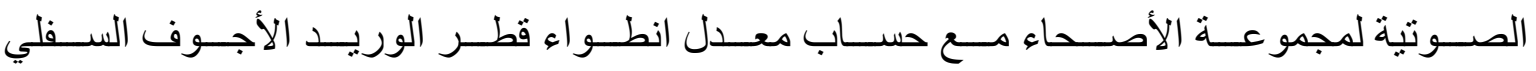
لكلتا المجمو عتين.

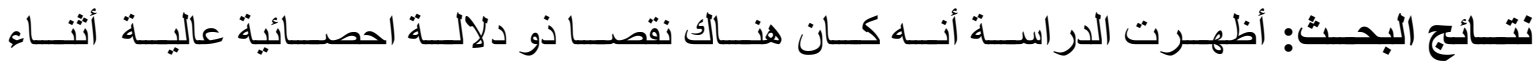

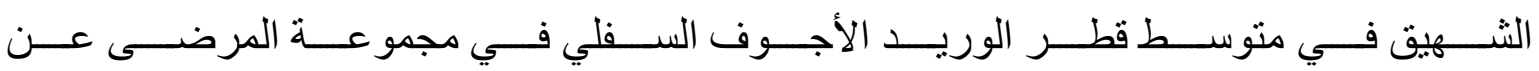

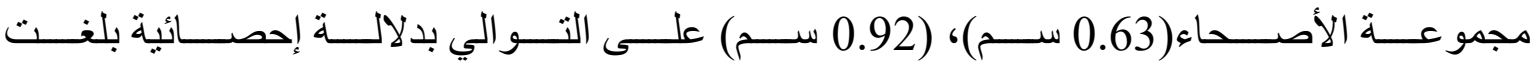

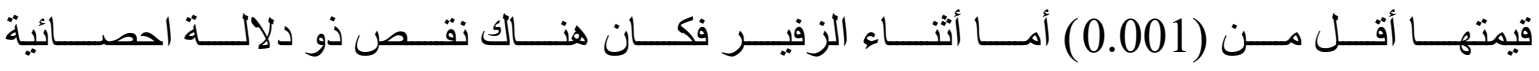

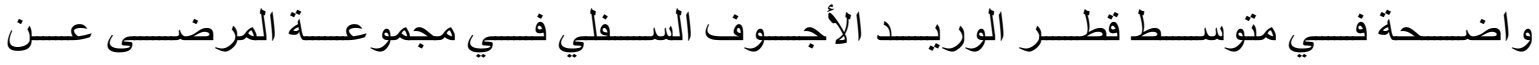

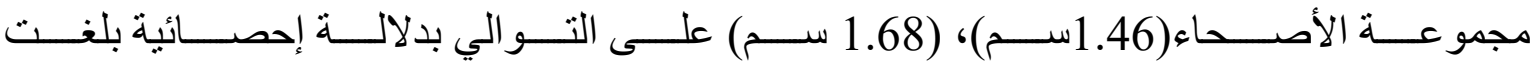

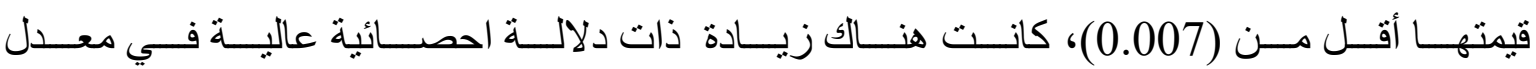

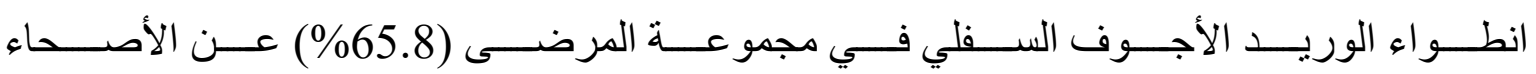
(45.5\%) بدلالة احصائية بلغت قيمتها أقل من (0.001).

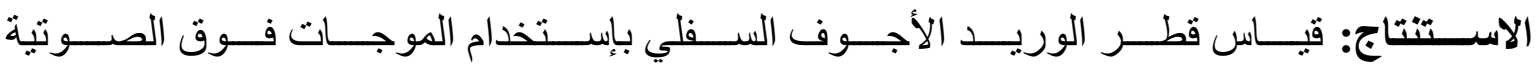

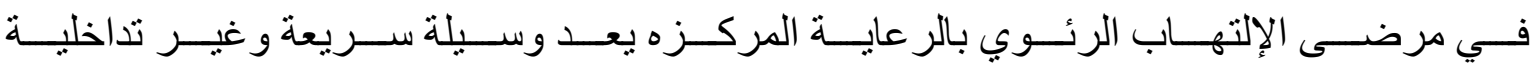

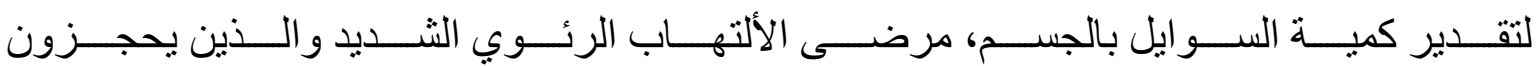

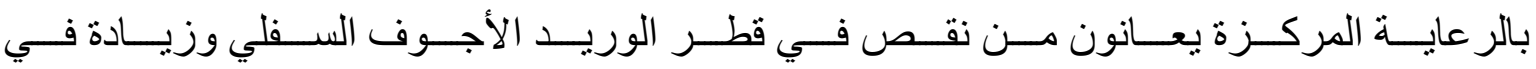
معدل انطو اءه نتيجة الى نقص كمية السوائل وجفاف الجسم.

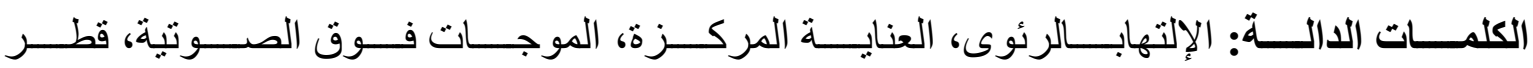
الوريد الأجوف السفلى. 